\title{
Evaluation of the Results of Primary Closure/Resection and Primary Anastomosis with Colostomy in Acute Colonic Injured Patients.
}

\author{
Habib ullah Shah ${ }^{1}$, Nawab Zada ${ }^{2}$, Muhammad Shoaib Khan ${ }^{3}$, Ishfaqullah Shah", \\ Atiq ullah Shah ${ }^{5}$ Qazi Rafi ud Din ${ }^{6}$
}

\begin{abstract}
Background: The management of acute colonic injury has been improved since several decades, treating low risk patients with primary closure and high risk patients (duration 6 hours or more, shock, contamination, transfusions 6 unit or more and multiple organs injury) with colostomy.

Objective: To assess the outcomes of primary closure and exteriorization in acute colonic injuries.

Material and Methods: This Comparative study was carried out in the Casualty Department DHQ teaching Hospital Bannu, from Jan.2009 to Dec.2010. Thirty Eight patients of acute abdominal trauma, who attended the emergency department, were included. Majority of the patients were those of fire arm injured, followed by blunt abdominal trauma. Less frequent were penetrating trauma due to stab and bomb blast pieces. As part of their resuscitation, they were shifted to operation theatre for abdominal exploration and either primary Closure/ Resection and primary anastomosis was done or colostomy of injured colon performed keeping in mind the Protocol of low and high risk categories respectively. The results obtained were subjected to statistical analysis by using SPSS software version 20 , and showed significant differences except wound infection when compared complications between primary closure \& Colostomy procedures.

Results: Primary Closure was carried out in 18 of 38 patients (47.4\%) in low risk category while Colostomy was done in 20 of 38 $(52.6 \%)$ in high risk patients. $(69 \%)$ of the patients were below 40 years of their age and $(31 \%)$ were above 40 years. In our series fire arm was more common (78.9\%) weapon for penetrating abdominal trauma. Isolated Colonic injury was rare $10.6 \%$ as colonic injury was usually associated with other organ injuries (89.4\%). Morbidity was comparable in both procedures. Wound infection recorded was (22\%) in Primary Closure \& $(20 \%)$ in Colostomy. Mortality recorded was $(5.5 \%)$ in Primary Closure \& $(10 \%)$ in Colostomy patients. Anastomotic leakage was recorded in one patient with primary closure where re colostomy saved the patient. Mean Hospital stay was 13days.

Conclusion: Primary Closure/Resection and Primary Anastomosis is having good results, in low risk patients but Colostomy of injured Colon is valuable in high risk and in patients who develop complications after Primary Closure.

Keywords: Colonic injury, Colostomy, Primary Anastomosis.
\end{abstract}

This article may be cited as: Shah UH, Zada N, Khan SM, Shah I, Shah UA. Evaluation of the Results of Primary Closure/Resection and Primary Anastomosis with Colostomy in Acute Colonic Injured Patients. J Saidu Med. Coll Swat 2020;10(1):74-78

\section{INTRODUCTION}

Isolated colonic injury is rare and is usually associated with other organs damage ${ }^{6,12,20}$ and also having high bacterial content and hard formed fecal loading ${ }^{9}$, increasing morbidity and mortality, through mechanical process and infecting the suture line. The initial symptoms and signs of isolated Colonic injury are vague, and delayed, as these are usually due to sepsis because of fecal spillage ${ }^{1,3,21,23}$ but as Colonic injury in abdominal trauma is usually associated with other abdominal organs injury ${ }^{6,12,20}$, therefore these patients usually are in critical conditions and present with pain, tachycardia, vomiting, bleeding, hypotension, distension of abdomen and signs of peritoneal irritation ${ }^{23}$.

1.Department of Anatomy, Bannu Medical College, Bannu.

2.Department of Physiology, Bannu Medical College, Bannu.

3.Department of Biochemistry, Bannu Medical College, Bannu.

4.Department of psychiatry \&Human behavioral sciences HMC, Peshawar.

5.Department of Biomedical sciences, Quaid-e-Azam university, Islamabad.

6.Department of Urology, Khlaifa Gul Nawaz Teaching Hospital, Bannu.

Correspondence: Dr. Habib Ullah Shah

Department of Anatomy, Bannu Medical College, Bannu

Email:drhabibullah45@gmail.com
The only solution for managing such patients is early laparotomy 7, 19, 21, 23, 27. Primary Closure/Resection and anastomosis in low risk and fit patients and otherwise colostomy is performed. Good surgical judgment and in time surgery may results in low morbidity and mortality 23, 24, 26. Keeping these in mind , the present study was conducted with the specific aim to compare the results of the primary anastomosis and colostomy in low and high risk categories respectively.

\section{MATERIALAND METHODS}

A comparative study, conducted in the casualty department of DHQ Teaching Hospital Bannu, from Jan 2009 to Dec 2010.

Total number of 38 patients with acute abdominal trauma, attended the emergency department. 30 of these patients $(78.9 \%)$ were those of fire arm injuries, followed by blunt abdominal trauma including 4 patients(10.5\%) other penetrating types of injuries were stab

Received October 28, 2019 Accepted March 2, 2020 
wounds 2 patients( $5.26 \%$ ) and bomb blast pieces penetrating were 2 patients $(5.26 \%)$. Most of these patients attended the casualty department in critical condition. So surgery was carried out as part of their resuscitation, based on the ATLS guidelines, taking brief history, detail abdominal clinical examination and performing only base line investigations, including blood grouping, cross matching, HBV, HIV, HCV, Blood urea, blood sugar and in exceptional stable cases ultrasound examination of abdominal pelvis and radiographs of cervical region, chest and pelvis were done on their way to operation theatre.

Inclusion criteria: All trauma patients with colonic injuries, irrespective of their age and sex with sero negative for HBS, HCV and HIV were included in the study, due to our surgical facility limitations.

Exclusion criteria: None of the above and nonwilling persons.

Statistical Analysis: Data were analyzed statistically, by using SPSS, version 20 , soft ware application and the results are presented in the form of tables, and $p$-values were calculated.

\section{RESULTS}

Most common of the associated injuries in order of decreasing frequency were small gut $(31.6 \%)$, liver (15.8\%),thoracic $(15.8 \%)$, stomach (15.8\%), Spleen $(10.5 \%)$, pancreatic, renal and urinary bladder injuries were also recorded in the minority of patients as shown in table 1.

In our patients operated, the most common of these were fire arm injured patients. We do not know the exact reason, but the incidence in our region has been especially increased after 9/11 ailment of the world. Other types of penetrating injuries were those of stab wound (5.26\%), bomb blast pieces penetration of the abdomen, leading to the colonic injury $(5.26 \%)$. Blunt type of abdominal injury with colonic involvement was second common cause, due to road traffic accident (10.5\%). As shown in table 2 .

Table 1. Showing \%age of associated organ injuries

\begin{tabular}{|c|c|c|}
\hline Associated organ injured & $\begin{array}{l}\text { Total number of } \\
\text { patients }\end{array}$ & \% age \\
\hline Small Gut & $\mathrm{n}=12$ & $\mathbf{( 3 1 . 6 \% )}$ \\
\hline Liver & $\mathrm{n}=6$ & $\mathbf{( 1 5 . 8 \% )}$ \\
\hline Thoracic injury & $\mathrm{n}=6$ & $\mathbf{( 1 5 . 8 \% )}$ \\
\hline Stomach & $\mathrm{n}=6$ & $\mathbf{( 1 5 . 8 \% )}$ \\
\hline Spleen & $\mathrm{n}=4$ & $\mathbf{( 5 . 2 \% )}$ \\
\hline Pancreas & $\mathrm{n}=2$ & $\mathbf{( 5 . 2 \% )}$ \\
\hline Renal & $\mathrm{n}=2$ & $\mathbf{( 2 . 6 \% )}$ \\
\hline Urinary bladder & $\mathrm{n}=1$ & $\mathbf{1 0 0 \%}$ \\
\hline Total & $\mathbf{3 8}$ & \\
\hline
\end{tabular}

Table 2. Showing \%age of Mechanism of Injury

\begin{tabular}{|c|c|c|}
\hline Mechanism of injury & Number of patients & \% age \\
\hline $\begin{array}{c}\text { Penetrating } \\
\text { Injuries (89.5 \%) }\end{array}$ & $\mathrm{n}=34$ & 89.5 \\
\hline 1. Fire arm & $\mathrm{n}=30$ & 78.9 \\
\hline 2. Stab wound & $\mathrm{n}=2$ & 5.26 \\
\hline 3. Bomb blast pieces & $\mathrm{n}=2$ & 5.26 \\
\hline $\begin{array}{c}\text { Blunt Trauma } \\
\text { 1.Road traffic accidents }\end{array}$ & $\mathrm{n}=4$ & 10.5 \\
\hline Total & $\mathbf{N}=\mathbf{3 8}$ & $\mathbf{1 0 0 \%}$ \\
\hline
\end{tabular}


Table 3. Comparison of complications between primary Closure \& Colostomy

\begin{tabular}{|c|c|c|c|}
\hline Major Complication & $\begin{array}{c}\text { Primary closure } \\
\text { patients } \\
(\mathbf{n = 1 8 )}\end{array}$ & $\begin{array}{c}\text { Colostomy } \\
\text { patients } \\
(\mathbf{n = 2 0 )}\end{array}$ & p-value \\
\hline Expiry & $1(5.5 \%)$ & $2(10 \%)$ & $\mathrm{p}<0.001$ \\
\hline Wound infection & $4(22 \%)$ & $4(20 \%)$ & Non-significant \\
\hline Burst Abdomen & $2(11 \%)$ & $1(5 \%)$ & $\mathrm{p}<0.001$ \\
\hline Anastomotic Break down & $1(5.5 \%)$ & $0(0 \%)$ & $\mathrm{p}<0.001$ \\
\hline
\end{tabular}

Hepatic, thoracic and stomach injuries were recorded in $(15.8 \%)$ of patients. splenic injury $(10.5 \%)$, pancreatic injury $(5.2 \%)$, renal and urinary bladder injuries were recorded in $2.6 \%$ of patients were infrequent ${ }^{19}$. Wound infection was comparable in both, primary closure $22 \%$ and colostomy $20 \%$. Two patients developed burst abdomen in primary closure and 1 patient in colostomy group. All these patients then underwent, tension sutures, and 1 of them of the primary colonic closure group, who along with burst abdomen, presented with leaked anastomosis, where besides undergoing tension sutures, exteriorization of the colon performed \& then the patient life was saved .The results showed significant differences between two groups, when compared complications like expiry, abdominal burst and anastomotic break down, between primary Closure \& Colostomy while non significant differences were observed in wound infection as shown in table 3.

\section{DISCUSSION}

In this modern era of huge overcrowding, poverty, lack of knowledge, with superadded terrorism and optimism, trauma is now a day's one of the most common cause of mortality and morbidity. Abdominal trauma is either penetrating or blunt, with most of the patients, having other associated injuries, including chest, skeletal and head injuries 23,30

Penetrating injuries include fire arm injuries, stab wounds, bomb blast pieces penetration, causing varieties of injuries. Velocity of the penetrating agent (Bullet) is also an important consideration , while penetration to the abdomen can also occur from injury to the thorax, loins, buttocks or perineum and then the involvement of other specialties concerned may become essential in the management of such patients, while following the ATLS guidelines, which also help avoiding, missing any injury ${ }^{1,23,30}$.
Non penetrating or blunt trauma include, crushing injuries, direct blows and deceleration forces injuries, some time there is no superficial wall trauma, in spite of intra abdominal organs injury. History, clinical examination of such patients and the knowledge of mechanism of injury is important in managing such patients ${ }^{30,31}$.

Most of these patients usually attended the casualty in their critical state of life, so surgery was carried out as part of the resuscitation for these patients, based on the ATLS guidelines, taking brief history, detail abdominal examination and performing only baseline and necessary investigations,. The usual symptoms and signs in the abdominal injury were pain, increased heart rate, vomiting ,increase in the size of abdomen, low BP, shock and signs of peritonism.

Experience of the surgeon and intelligent interpretation of history, clinical findings, along with available laboratory procedures, may be of some help but laparotomy is ultimately, the definitive procedure to detect the colonic injury early and to avoid the serious complication of delay, once there is peritoneal penetration. So surgery was done as part of resuscitation with generous midline abdominal incision through which all of the abdominal organs may be easily examined and can beextended, where needed.

The aim was to save these patients with minimal morbidity and mortality. IV fluids in the form of Ringolact $D$ infusion was started while blood transfusion arrangement was being made. During laparotomy all abdominal organs were examined and it was observed that isolated Colonic injury was rare $(10.6 \%)$, as compared to injured colon along with other associated injuries (89.4\%), most common of the associated injuries in order of decreasing frequency were small gut $(31.6 \%)$, liver (15.8\%),thoracic $(15.8 \%)$, stomach (15.8\%), Spleen (10.5\%), pancreatic, renal and urinary bladder injuries were also recorded in the minority of patients as shown in table 1. 
Either colostomy (20 of 38 patients $52.6 \%$ ) or primary closure/resection and anastomosis of injured colon were carried out (18 of 38 patients $47.41 \%)$. Colonic injuries were categorized into low and high risks, depending upon the duration of injury ${ }^{21,}{ }^{23}$ whether more or less than 6 hours, age of the patients above or below 40 years, general condition of the patient and whether or not associated with other injuries and nature of severity and number of such associated organs injuries, the low and high risk categorization also require good surgical judgment, any associated co morbid factors and degree of fecal spillage ${ }^{21,23}$ in addition to the above. Most of the patients in this series were less than 40 years of age $(69 \%$ versus $31 \%)$. Male predominated over females (94.7\% versus $5.2 \%)$; penetrating injury was more common than non penetrating $(89.5 \%$ versus $10.5 \%)$. Fire arm injury was the commonest weapon for penetration in our series $(78.9 \%$ versus $5.26 \%$ stab versus bomb blast $5.26 \%$ ), small gut injury was the commonest associated organ injury. Colonic injury related morbidity \& mortality were analyzed. As symptoms of isolated injury of the colon are usually delayed and usually are due to sepsis, because of peritoneal fecal contamination, ${ }^{1,3}$ resulting in complications, if management is delayed ${ }^{29}$.

Only early surgical intervention avoid such sequelae of fecal spillage ${ }^{21,23,24,25,27,29}$ such as abscess formation, peritonitis, multi organs failure and death, but as colonic injury is usually associated with other organs injury so this along with age of the patient, general condition of the patient \& any other associated co morbid factors can significantly affect the outcome ${ }^{29}$.

In our series the patients with colonic injuries, primary closure was performed in $(47.3 \%)$ and colostomy done in $(52.7 \%)$ of patients and where $95 \%$ were male and only $5 \%$ were female, $69 \%$ of the patients were below age of 40 years and $31 \%$ were above 40years. This resembles other international literature available ${ }^{19}$. Fire arm injured patients predominated $(79 \%)$ and 2 patients $(5.2 \%)$ each in stab and bomb blast, were present. Total 4 patients $(10.5 \%)$ were present in blunt trauma due to road traffic accident. This simulates in that, penetrating injury predominates over none penetrating ${ }^{29}$ but it is dissimilar in kind of weapon used. Small gut injury was the commonest $(31.6 \%)$ of the associated organ injuries which simulates the available international series ${ }^{19}$.
Hepatic, thoracic and stomach injuries were recorded in $(15.8 \%)$ of patients. spleenic injury $(10.5 \%)$, pancreatic injury $(5.2 \%)$, renal and urinary bladder injuries were recorded in $2.6 \%$ of patients were infrequent [19]. Wound infection was comparable in both, primary closure $22 \%$ and colostomy $20 \%$. Two patients developed burst abdomen in primary closure and 1 patient in colostomy group. All these patients then under went, tension sutures, and 1 of them of the primary colonic closure group, who along with burst abdomen, presented with leaked anastomosis, where besides undergoing tension sutures, exteriorization of the colon performed \& then the patient life was saved see table 3.

Matalo et al also revealed lesser chances of complications and decreased expiry rate in patients, undergoing initial closure in injured colon $^{3}$. Shannon et al also has set guidelines following colonic injuries and report good results, performing primary closure in colonic injuries, if perforation is small with minor fecal soiling, having good vascularity and if the patient is hemodynamically stable ${ }^{1}$.

\section{CONCLUSION}

Although still colostomy is a valuable procedure, in high risk group, but according to our experience, primary anastomosis may be a safe option in low risk patients.

\section{REFRENCES}

1. Shannon FL; Moree EE; Primary Repair of the colon. When is it a safe alternative? Surg 1985;98; 851-57.

2. Corn well Ee 111, VelmahosGC, Berne T.V et al. The fate of colonic suture lines in high risk trauma patients. A prospective analysis. J. Am coll Surg;1998;187(1);5863.

3. Matolo NM, Wolfman ER. Primary repair of colonic injuries. A clinical evaluation; J. Trauma1997; 17; 55456.

4. Ganzalez RP, Merlotti GJ, Holevar MR. Colostomy in penetrating colonic injuries. Is it necessary? J .Trauma 1996; 41(2) 271-75.

5. Zorcolo L , Covotta L, Carlomagno $\mathrm{N}$ et al ; safety of primary anastomosis in emergency colorectal Surgery ; Colorectal Dis 2003; (5); 262-69.

6. Sasaki Ls, Allaben RD, Golwala R, et al; Primary repair of Colonic injuries ; A prospective Randomized trial; Am Surg. (1995); 39(5); 895-901.

7. Negrete; Polido OR, Molina, Torres $\mathrm{M}$ et al. Colonic perforation during $\mathrm{PCNL}$, Prevention, Diagnosis and Treatment. Rev Mex. Urol 2010; 70(1), 44-47.

8. Chappuis CW, Frey DJ, Diezan C et al. Management of penetrating colonic injuries . A prospective randomized trial . am sur (1991);213(5); 492-98.

9. A sule, PO. Obepka, OGBOWNA et al; intra operative colonic irrigation in the management of left sided Large bowl emergencies in Jos university Teaching Hospital Nigeria; JEAM $2007 ; 77: 11$. 
10. Burch JM, Martin R, Richardson RJ. et al. Evolution of the treatment of the injured colon in the 1980's ; Arch surg;1991; 126: 976-84.

11. Wen YY; Mein-Kai G, Shih- Ming H et al; Acute colonic intra mural hematoma due to blunt abdominal trauma ; Int surg 2000; 85; 51-54.

12. Curran TJ, Bot Zotta AP. Complications of Primary repair of colon injury : Am J. Surg (1999); 177; 42-47.

13. Cho, S.David MDI, Kiraly Laszole N. MDI et al; Management of colon injuries in combat theater . Gastroenterology Nursing . 2007, 30:(5): 337-41.

14. Murray JA, Demetriades D, Colson M. et al, Colon resection in Trauma; colostomy versus anastomosis . J Trauma 1999;177; 42-47.

15. Ross SE, Cobean RA, Hoyt DB, et al; Blunt colon injury .Review J Trauma 1992; updated 2016; 33:379-84.

16. Stewart RM, Fabian TC, Croce MA, et al . Is resection with primary anastamosis, following Destructive colon wounds always safe?. Am J surg 1994; 168; 316-19.

17. Irvin TT, Goligner TC. Aetiology of disruption of intestinal anastomosis . Brit J. Surg 1973; 60; 461-64.

18. N. Wafo Dc. Selective primary suture of the battle injured colon. An experience of the Nigerian civil war : Brit. J. Surg 1980; 67; 195-97.

19. Siddique MAB, Rahman MK, Hannan ABMA; Study on abdominal injury; An Analysis of 50 Cases; TAJ 2004: 17(2); 84-88.

20. TZovara SG, Hatzitheofilouc; New trends in the Management of colonic trauma . Injury 2005; 36; 101115.

21. Normann SW, Christopher JK, Bulstrode P, Ronan O, Connell. Bailey's and Love's; Short- Practice of Surgery $26^{\text {th }}$ Edition Vol. $1 ; 361$.
22. Bowley DM, Boffard KD, Goasen J, et al. Evolving concepts in the management of colonic injury: Injury 2001; 32: 435-39.

23. SIR Alfred Cuschieri, Robert J, Steele C, Moossa AR; Essential Surgical Practice, Higher Surgical training in General Surgery, $4^{\text {th }}$ edition vol 2 Part I ; 26.

24. Samy A, Azer John G et al ; Med Scape Reference ; Intestinal perforation, updated 11 May; 2011.

25. Prasid ML,Abcarian H, Read DR, et al. Acute care surgery, principles and practice: Dis; Colon rectum 1981; 24: 456-62.

26. Pankaj J. Colonic Injuries, Surgery in Africa- monthly review, when is primary anastomosis Safe in the colon? July 2005 review \& March 2010 updated,

27. Rene G, Holzheimer, John AM. Surgical Treatment, Evidence based \& problem oriented; Department of Surgery, Harvard University, Medical School USA; :2001.

28. Cleary RK, Pomevantz RA; Lampman RM. Colon and rectal injuries ; Dis Colon Rectum 2006; 49:1203-22.

29. Yi X Z, Li C, Si F, Tao, et al. Diagnosis and management of colonic injuries, following blunt trauma world $\mathrm{J}$ Gastroentrol 2007, 13; 4 :633-36.

30. Khan, M. Abdominal trauma. In Trauma: Code Red 2018. CRC Press.189-232.

31. Torba, M., Gjata, A., Buci, S, Bushi, G., Zenelaj, A, Kajo, I, Subashi, K.. The influence of the risk factor on the abdominal complications in colon injury management. I/ Giornale di chirurgia, 2015;36(2), 57. 